\title{
História e Narrativa: Princípios Conceituais
}

MALERBA, Jurandir (Org.). História \& Narrativa: a ciência e a arte da escrita histórica. Petrópolis: Vozes, 2016.

Robson Bertasso $^{1}$

Lançado no ano de 2016 pela Editora Vozes, o livro História \& Narrativa: a ciência e a arte da escrita histórica, organizado por Jurandir Malerba, professor titular da UFRGS, traz ao público uma série de artigos inéditos em língua portuguesa, que versam sobre temas relacionados à teoria da história, tendo como âmago o debate envolvendo história e narrativa, cujas origens remontam à década de 1960 e ao linguistic turn.

Composta por textos de autores brasileiros e estrangeiros, alguns já publicados em grandes revistas acadêmicas internacionais, como a History and Theory, esta antologia objetiva disponibilizar ao leitor, em especial aos estudantes do curso de História, elementos para a compreensão de um debate que, embora antigo, permanece atual. Tratase, como aponta Valdei Lopes Araújo no prefácio da obra, de uma iniciativa comprometida com a formação do historiador brasileiro, que "encara a tarefa teórica como central à sua atividade"2.

\footnotetext{
${ }^{1}$ Graduando do $6^{\circ}$ período do curso de bacharelado em História - Memória e Imagem pela UFPR.

${ }^{2}$ ARAÚJO, Valdei Lopes. Prefácio. In: MALERBA, Jurandir (Org.). História \& Narrativa: a ciência e a arte da escrita histórica. Petrópolis: Vozes, 2016, p. 14.
} 
Por se tratar de uma obra com artigos diversificados, que abrangem vários aspectos da história e da narrativa, focar-me-ei na leitura do primeiro bloco temático do livro, composto por textos de Jurandir Malerba, Allan Megill, Jörn Rüsen e Jerzy Topolski, a fim de discutir os princípios conceituais gerais da narrativa histórica.

No primeiro capítulo do livro, Jurandir Malerba introduz ao leitor o primeiro bloco temático da obra, reconstituindo as origens do debate em torno da narrativa e da história. Conforme o autor, até a década de 1960, a história consolida seu campo de atuação dentro das chamadas ciências sociais, voltando suas discussões e reflexões, principalmente, ao trabalho metodológico, deixando de lado aspectos relacionados à epistemologia do conhecimento histórico. Este cenário se altera quando ocorre o chamado linguistic turn, na década de 1960, momento em que diversos intelectuais oriundos de outras áreas questionam o estatuto científico da história. Malerba argumenta que, a partir deste momento, o foco das reflexões "deixou de ser a história processo ou os parâmetros da pesquisa metodicamente regulada para recair sobre os protocolos constitutivos do discurso historiográfico"3. Doravante, tanto intelectuais de outras áreas como historiadores debruçaram-se, sobretudo, em discussões envolvendo o caráter narrativo da historiografia, fato este que desencadeou uma série de impasses sobre qual seria a natureza do conhecimento histórico. De ${ }^{3}$ MALERBA, Jurandir. Ciência e arte na escritura histórica. In: MALERBA, op.
cit., p. 17. 
ciência à literatura, assim as questões foram se apresentando no seio das discussões.

No capítulo seguinte, o primeiro dos que percorrem questões específicas ao debate, Allan Megill explora um termo pouco usual entre os acadêmicos brasileiros, chamado historiologia. Este termo se refere, especificamente, a "um discurso meta-histórico preocupado com o trabalho feito pelos historiadores" ${ }^{\prime 4}$ e se difere da chamada filosofia da história, que, embora seja utilizada esporadicamente para se referir às reflexões sobre a prática historiográfica, abrange aspectos mais gerais de compreensão da história.

Conforme o autor, ao final do século $\mathrm{XX}$, quatro grandes tradições de historiologia consolidam-se no cenário acadêmico: analítica, hermenêutica, idealista e linguístico-narrativa. Os três primeiros casos compartilham da mesma raiz, pois surgiram das discussões ocorridas entre a segunda metade do século XIX e início do $\mathrm{XX}$, envolvendo a natureza epistemológica das ciências humanas, e dos embates em torno da proclamação científica da história e da crescente influência das ciências naturais e do positivismo. Foram importantes contribuições a esses debates os trabalhos de Wilhelm Windelband, que propôs a distinção entre as ciências nomotéticas, caracterizadas pela busca e estabelecimento de leis universais, e as ciências ideográficas, encarregadas de estudar realidades particulares, das quais a história seria uma representante; de Wilhelm Dilthey, que, buscando evitar

${ }^{4}$ MEGILL, Allan. Historiologia/filosofia da escrita histórica. In: Ibid., p. 35. 
qualquer hierarquização entre as ciências, argumentou que elas possuem naturezas distintas, sendo as ciências naturais baseadas no método da explicação e as ciências humanas no método da compreensão; e de Max Weber, que apontou que a história possui ambas as dimensões, tanto explicativa, como interpretativa. Assim, apresentado o cerne das discussões que serviram de palco para o surgimento da historiologia, o autor explica no decorrer do capítulo como cada uma das três tradições contribuiu para o debate envolvendo o papel da narrativa na escrita da história. Em um primeiro momento, na analítica, a narrativa é relacionada ao modelo de lei de cobertura, proposto pelo filósofo positivista Carl G. Humpel na década de 1940; em um segundo, na hermenêutica, a narrativa torna-se protagonista das discussões, com os trabalhos de Paul Ricoeur e Paul Veyne; e por fim, na idealista, refletiuse sobre a prática historiográfica, constatando que a história é um construto do presente, fato que abriu espaço para o surgimento da última tradição, a linguístico-narrativa. Como pode-se observar, esta tradição possui uma origem distinta das anteriores, pois foi desenvolvida no seio das discussões ocorridas entre 1960 e 1970, ou seja, pelo linguistic turn e pela filosofia pós-estruturalista. Nomes como o do teórico literário Roland Barthes, do filósofo Louis Mink e do historiador Hayden White figuram entre os principais deste contexto. Em linhas gerais, a historiologia linguístico-narrativa se define por perceber a obra de história como um construto linguístico em dois sentidos: o primeiro por ela ser "construída a partir da linguagem de 
formas complexas que pode ser entendida apenas se alguém analisá-las como os acadêmicos e os críticos literários analisam as obras de literatura"5, e o segundo porque o historiador faz uso de recursos literários para construir sua análise sobre o passado, ou seja, a historiografia. Essas quatro tradições historiológicas, analítica, hermenêutica, idealista e linguístico-narrativa, representam, conforme Megill, o desafio da multiplicidade de temas e abordagens que o historiador do século XXI pode escolher.

$\mathrm{Na}$ sequência da obra, o texto de Jörn Rüsen, Narração histórica: fundações, tipos, razão, empenha-se em realizar uma tarefa extremamente complexa, muitas vezes ignorada pelos historiadores, de explicar o que é uma narração histórica. Para além da singela fórmula proposta por Hayden White, que considera a história "como uma estrutura verbal na forma de um discurso em prosa narrativa" ${ }^{\prime}$, Rüsen entende a narração histórica como uma rede de operações mentais que compõem e definem a consciência histórica ${ }^{7}$ de um determinado grupo social. Em síntese, trata-se da maneira como os seres humanos dão sentido ao passado. Para o autor, a narração histórica possui três características que se relacionam: em primeiro lugar, ela está intimamente associada à mediação da memória; em segundo, ela

\footnotetext{
${ }^{5}$ MEGILL, Allan. Historiologia/filosofia da escrita histórica. In: MALERBA, op. cit., p. 42.

${ }^{6}$ RÜSEN, Jörn. Narração histórica: fundações, tipos, razão. In: Ibid., p. 45.

${ }^{7}$ Para mais informações sobre a Teoria da Matriz Disciplinar de Jörn Rüsen, cf. RÜSEN, Jörn. Teoria da História: uma teoria da história como ciência. Trad. Estevão C. de Rezende Martins. Curitiba: Editora UFPR, 2015.
} 
organiza as três dimensões temporais - passado, presente e futuro - por meio do conceito de continuidade; e por fim, ela serve para estabelecer a identidade de seus autores e ouvintes ${ }^{8}$.

A grande contribuição de Rüsen consiste em ir além de propor apenas uma explicação para o campo historiográfico, como fez Hayden White, pois ele esboça um quadro tipológico de como sua teoria da narração histórica se aplica na vida social. Este quadro é dividido em quatro tipos de narrativas - tradicional, exemplar, crítica e genérica - e em quatro aspectos - como a memória é trabalhada, a continuidade e a identidade desenvolvidas e o tempo sentido. Assim, desde práticas como a construção de monumentos até o empreendimento de obras literárias que visam tirar valores do passado ou promover críticas ao presente, compõem o mosaico das narrativas. Mas seria possível associar a historiografia a alguma dessas quatro narrativas? Para o autor, certamente que sim. O uso da tipologia na análise historiográfica possui uma série de funcionalidades, que permitem, por exemplo, desenvolver uma classificação de obras históricas, esboçar uma periodização da história da historiografia, entre outras atividades. Contudo, sua principal função é fornecer os meios para se compreender que a historiografia é um construto mutável, que na medida em que a mudança temporal ocorre, a estrutura da narração histórica se modifica. A Geistesgeschichte não é uma esfera autônoma da história geral, mas, sim, um espelho dela.

\footnotetext{
${ }^{8}$ RÜSEN, op. cit., p. 48.
} 
Tendo em vista essas questões, resta compreender como a historiografia é materializada pela narrativa, e é o texto do historiador polonês Jerzy Topolski que fornece uma excelente chave de leitura para isso. A escrita da história, chamada pelo autor de "totalidade narrativa", constitui-se no entrelaçamento da argumentação lógica, que faz parte do caráter científico da disciplina, com a inspiração estética. Topolski argumenta que o material primário com o qual o historiador trabalha a narrativa histórica é a "informação básica", que consiste em enunciados/proposições de fontes que, por sua natureza, são de livres interpretações e que variam de tema para tema. Assim,

construir uma narrativa significa combinar um número de pedaços de informação básica mais ou menos dispersos, nunca se referindo a "todas as coisas", em uma totalidade textual coerente: metaforicamente, é a transformação de numerosos pontos únicos em linhas contínuas e superfícies. O historiador passa de enunciados únicos para generalizações e totalidades narrativas integradas (coerentes). ${ }^{9}$

Para se compreender o caráter das narrativas históricas o autor propõe uma análise dividida em duas etapas: a primeira chamada de horizontal e a segunda de vertical. No primeiro caso, sua atenção é voltada à maneira como uma narrativa histórica é estruturada. Para Topolski, a narrativa histórica não se constitui por uma simples

${ }^{9}$ TOPOLSKI, Jerzy. O papel da lógica e da estética na construção de totalidades narrativas na historiografia. In: MALERBA, op. cit., p. 62. 
sequência de enunciados, mas, sim, por uma lógica teleológica empregada às "pequenas totalidades narrativas", ou seja, na estruturação dos parágrafos, dos subcapítulos, dos capítulos, etc., que, adquirindo cada vez mais significado, compõem as complexas totalidades narrativas de uma obra. Este fenômeno é chamado pelo autor de "ligação de conteúdo". No segundo caso, Topolski mostra que as narrativas históricas são compostas por três níveis: a subestrutura, que se refere às imagens do passado que um determinado historiador almeja passar ao seu leitor; a subestrutura retórica, que é o nível de persuasão do historiador, que inclui a utilização de figuras de linguagem como clímax, anticlímax, prolepse, exclamação, ironia, entre outras; e a subestrutura de política, que se refere à visão de mundo do narrador/historiador que se reflete no texto, ou seja, seus valores endossados. Conclui-se, a partir de Topolski, que a narrativa histórica é uma estrutura persuasiva construída pelo historiador através de recursos lógicos e estéticos a fim de transmitir um conteúdo específico a um determinado público.

Os textos aqui discutidos foram produzidos em contextos diferentes, por historiadores oriundos de circuitos acadêmicos distintos, o que pode nos revelar que a preocupação envolvendo a questão da narrativa na historiografia é um fenômeno global. Trata-se de um debate que foi retomado há mais de quarenta anos internacionalmente e que no Brasil, até meados dos anos 1990, era tratado majoritariamente como periférico por parte dos historiadores. Tendo isso em vista, a obra 
organizada por Malerba faz parte de um esforço maior de uma nova geração de historiadores brasileiros preocupados com questões teóricas envolvendo a escrita da história.

Recebido em 31/12/2016, aceito para publicação em 22/07/2017. 